\title{
Malondialdehyde concentrations in obsessive-compulsive disorder: a systematic review and meta-analysis
}

\author{
Amir Hossein Mohammadi ${ }^{1,2}$, Ebrahim Balandeh ${ }^{3 \dagger}$ and Alireza Milajerdi ${ }^{*}$
}

\begin{abstract}
Background: This meta-analysis aimed to investigate serum and plasma malondialdehyde (MDA) levels in patients with obsessive-compulsive disorder (OCD) in comparison to healthy controls.

Methods: Following the PRISMA protocol, we searched for the relevant studies through the databases of Scopus, PubMed, Google Scholar, and web of science until September 2019 with no time restriction. Overall, nine studies were included in the current meta-analysis. Data were pooled using a random-effects model; in addition, standard mean difference (SMD) and/or weight mean difference (WMD) was calculated. Cochran's Q test and I-square $\left(I^{2}\right)$ statistics were used to evaluate between-study heterogeneity. The Newcastle-Ottawa scale (NOS) was used to evaluate the quality of the included studies. Statistical analyses were done using the STATA version 14.

Results: Our systematic review included nine case-control studies (including 367 cases and 337 controls). Pooling findings from these studies showed a significantly higher MDA level in OCD patient compared to control groups $\left(\mathrm{SMD}=1.62 ; 95 \% \mathrm{Cl}[0.53,2.72] ;\left.\right|^{2}=96.9 \%\right.$; Pheterogeneity $\left.(\mathrm{Ph})<0.001\right)$. This finding remained unchanged among studies which reported MDA in the same unit (WMD $\left.=1.93 ; 95 \% \mathrm{Cl}[0.27,3.59] ;\left.\right|^{2}=99.2 \% ; \mathrm{Ph}<0.001\right)$. Subgroup analysis by the study location and sample size revealed findings that were also significant.
\end{abstract}

Conclusion: We found that MDA levels are higher in OCD patients than healthy controls. This finding highlights the importance of inflammatory responses in OCD patients that should be considered for future investigations. Further studies are recommended to expand current knowledge on this issue.

Keywords: Oxidative stress, Malondialdehyde, Obsessive-compulsive disorder, OCD, Meta-analysis

\section{Introduction}

Obsessive-compulsive disorder (OCD) is characterized by intrusive, unwanted, and disturbing thoughts, images, and urges (obsessions) that elicit significant distress and repetitive behavioral or mental compulsions [1]. Such compulsions may lead to a temporary reduction in

\footnotetext{
*Correspondence: amkhv@yahoo.com

†Ebrahim Balandeh Co-first author

${ }^{2}$ Research Center for Biochemistry and Nutrition in Metabolic Diseases,

Institute for Basic Sciences, Kashan University of Medical Sciences (KAUMS), Kashan, Iran

Full list of author information is available at the end of the article
}

distress [2]. About $0.5-3 \%$ of people suffer from this disorder $[3,4]$ which influences social relations, quality of life, and occupational functioning [5-7]. Moreover, family members of the patients who live with him/her are also affected by the disorder [8].

Oxidative stress (OXS), resulting from imbalances between the generation of oxidative free radicals in the body and neutralizing antioxidants, plays an important role in the pathophysiology of OCD [9]. OXS can cause several damages to the brain, including disruption of the membrane integrity, damages caused by the peroxidation of lipids, proteins, and nucleic acids, and changes in natural neuronal apoptosis [10]. Free oxygen radicals 
have been recently acknowledged as great risk factors in the pathogenesis of several diseases, including neuropsychiatric disorders $[11,12]$. OXS also influences the genes responsible for various psychiatric disorders, including obsessive-compulsive disorder and other anxiety disorders $[9,13]$. Failure to regulate endogenous oxidative processes leads to brain insult, which may be implicated in various psychiatric disorders [14]. OXS may damage, modify, and denature the chemical structure of fatty acids [15]. Emerging evidence suggests that OXS and inflammation accelerate cellular aging and neuroprogression [16]. The brain is particularly vulnerable to the deleterious effects of OXS. Studies have linked OXS to bloodbrain barrier disruptions, altered patterns of neural growth, and changes in brain morphology $[17,18]$. This condition can cause psychological stress-related mental illnesses [16] and neurobehavioral disorders [19]. Therefore, the measurement of OXS in patients with OCD is important.

Malondialdehyde (MDA) is a natural product of peroxidation of unsaturated fatty acid with three or more double bonds. MDA concentration is usually measured by the thiobarbituric acid reacting substances test (TBARS), which is known as a simple and non-specific test [20]. MDA measurement is a reliable method and is known as one of the most popular methods for determining the status of OXS in clinical settings [20]. Moreover, MDA has been found in brain centers and its factors play crucial roles in the pathogenesis of neurodegenerative diseases [21]. Earlier studies have measured serum MDA levels in OCD patients compared to healthy controls [22, 23]. Results suggested higher free radical metabolism in OCD and therefore tissue damage due to OXS [22]. However, few studies have summarized their findings to reach a firm conclusion. Although a meta-analysis in 2019 investigated levels of oxidative and nitrosative markers in patients with OCD [24], that study had several limitations [25] including missing some relevant publications [26, 27]. In addition, the authors pooled data with different units in their meta-analysis, possibly leading to invalid results. A similar study by Oliveira et al. also had the same limitations [28]. Oliveira et al. suggested that "Ozdemir et al. was in fact selected for systematic review, but excluded from quantitative analyses, as stated in the PRISMA flow diagram"; however, they referenced Ozdemir et al. in included studies in Maia et al. [24]. Due to these mistakes, reaching a firm conclusion seems impossible. By contrast to the limitations of the prior study, ours had some strengths, namely in our systematic review, we included more studies with controversial findings and also including a sufficient number of studies allowed us to do subgroup analysis, all of which contribute to a more reliable conclusion.
As mentioned above, OXS greatly influences brain function and might influence disease prognosis in patients with OCD. Therefore, the measurement of OXS is crucial for these patients. MDA is a known independent marker of OXS and inflammation that has been frequently measured in such patients. Although several earlier studies have been published about serum levels of MDA in patients with OCD, there is still the need to summarize their findings. Measurement of MDA in patients with OCD compared to healthy controls gives us important information about OXS in these patients and the accuracy of MDA measurement for detection of OXS and for expectation of disease prognosis. Therefore, we aimed to conduct current systematic review and metaanalysis to summarize findings from earlier studies in which MDA was measured in OCD patients compared to healthy controls. It should be mentioned that among different markers of OXS, sufficient data were available only for MDA levels.

\section{Methods \\ Search strategy}

The present study was performed based on the PRISMA protocol for reporting systematic reviews and metaanalyses [29]. A systematic search was done by two independent investigators (AM and $\mathrm{EB}$ ) through databases of PubMed, Web of Science, Science Direct, Scopus, and web of science on relevant studies published up to December 2019. Keywords used in our search strategy were: (("Obsessive-compulsive disorder" OR "Obsessive-compulsive disorder" " OR "OCD" OR "Obsessive-compulsive" OR "Obsession" OR "Compulsion" OR "Obsess" OR "Compuls" OR "Obsessive*-compulsive" OR "Obsessive-compulsive" OR "Obsessive"-compulsive" OR "Anankastic"[MESH]) AND ("MDA" OR "Malondialdehyde" OR "Malonyldialdehyde" OR "Propanedial")). No restriction was made in terms of publication time or language. Also, the reference lists of relevant papers were reviewed to avoid missing any publication. Data from unpublished studies were not included. If two studies were published on the same set of data, we included only the most complete one [30].

\section{Inclusion and exclusion criteria}

In this meta-analysis, publications with the following criteria were considered to be eligible: (1) studies in which OCD cases were diagnosed according to the Diagnostic and Statistical Manual of Mental Disorders (DSM-III or later edition), or its equivalent in the International Classification of Diseases (ICD); (2) studies that evaluated MDA levels in patients with OCD; (3) studies that recruited healthy subjects as controls; (4) those that reported mean \pm standard deviation (SD) MDA level 


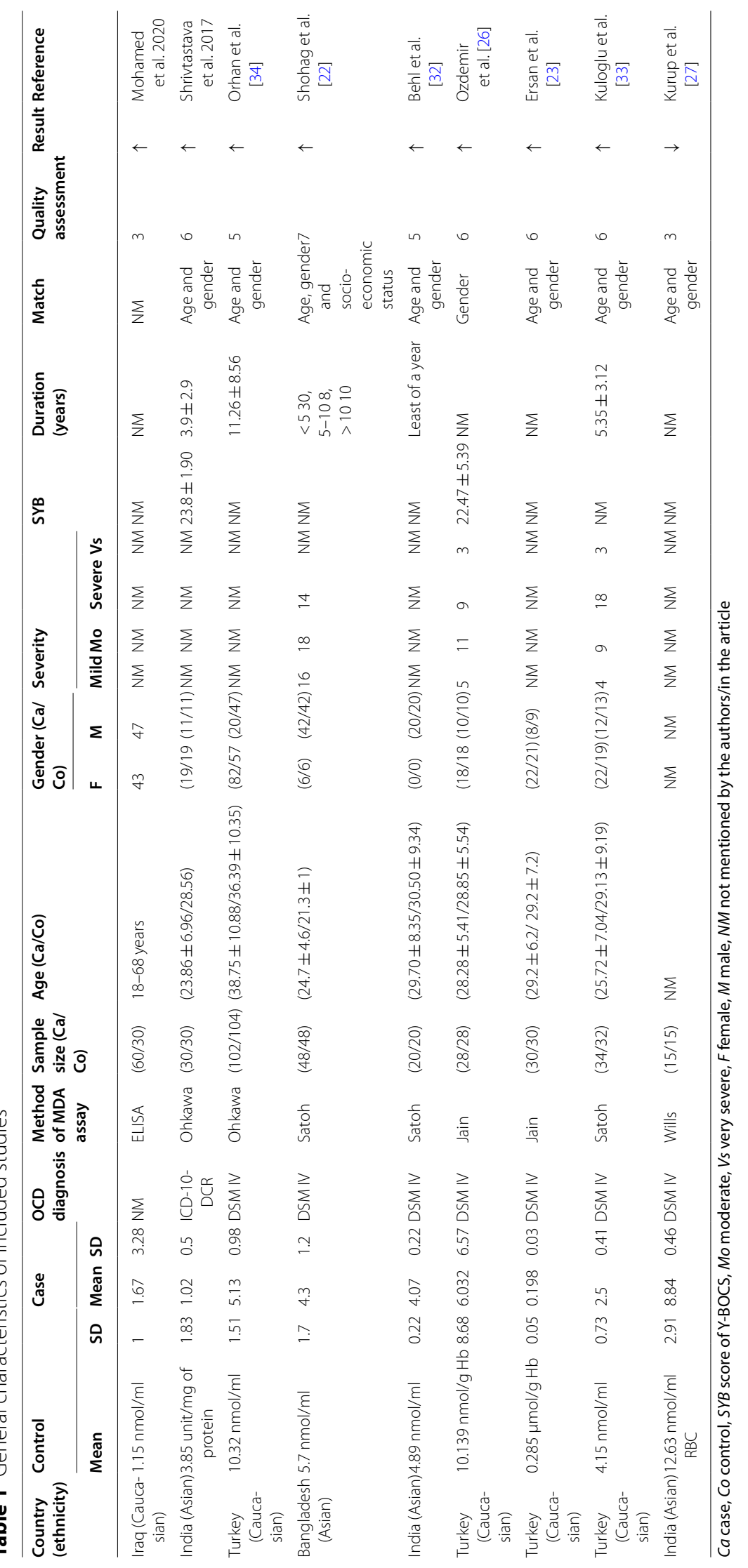


along with 95\% confidence intervals. Letters, comments, short communication, reviews, meta-analyses, ecological studies, and animal studies were also excluded.

\section{Data extraction}

Necessary data were extracted from included studies by two independent reviewers. All reported mean \pm SD for the MDA level compared with the healthy control group were extracted. We obtained the following information from each study: first author's name, year of publication, country of origin, the age range at study baseline, gender, sample size, study design, number of participants, methods used for assessing MDA levels and OCD, and any adjustments for confounding variables (Table 1 ).

\section{Quality assessment}

The Newcastle Ottawa scale (NOS), designed for observational studies, was used to assess the quality of selected studies [31]. The NOS gives a maximum of ten-point to each study: five for selection, two for comparability, and three for outcome assessment (ten represented the highest quality). Any discrepancies were resolved by discussion. In the current study, those studies with a NOS score of 5 or more were considered high-quality publications (Table 1).

\section{Statistical analysis}

We pooled mean \pm SD of MDA levels reported in persons with OCD compared to control groups using a randomeffects model. To assess between-study heterogeneity, the Cochrane $\mathrm{Q}$ test and $\mathrm{I}^{2}$ statistics were used. Betweenstudy heterogeneity was considered significant when $\mathrm{I}^{2}$ values were $50 \%$ or more. Besides, we conducted subgroup analyses by the predefined criteria to find probable sources of heterogeneity. Statistical analyses were done using STATA version 14 (StataCorp).

\section{Results}

\section{Characteristics of included studies}

Our systematic review included nine case-control studies $[22,23,26,27,32-36]$. Figure 1 presents a flow diagram for study selection. The characteristics of these studies are shown in Table 1. The sample size of these studies varied from 30 to 206 [total: patient 367 (women 57\%, men 43\%) and control 337 (women 49\% men 51\%)]. The mean age of patients was 28.6 years and the mean age of control was 29.13 years. The included studies were published between 2002 and 2019. Four studies were conducted in Turkey $[23,26,33,34]$, three in India [27, $32,35]$, one in Bangladesh [22], and Iraq [36]. Among the studies, one was conducted on male subjects [32], the six were conducted on both genders [22, 23, 26, 33-35], and two other studies did not report the gender of the subjects $[27,36]$. The mean disease duration ranged from 3.9 to 11.26 years. OCD was diagnosed based on DSM-IV in seven studies [22, 23, 26, 27, 32-34], while one study used ICD-10-DCR [35] and one study did not report the diagnostic method [36]. In addition, two studies used Y-BOCS to assess the severity of OCD [26, 35]. Moreover, few studies did not report the Y-BOCS outcome [22, 23, 27, 32-34, 36]. MDA level was measured based on the method developed by Satoh [22, 32, 33], Ohkawa [34, 35], Jain [23, 26], Wills [27] and one study used ELISA method [36]. Not having enough access to sufficient data, we could not unify all studies.

\section{Results from meta-analysis}

The results of overall and stratified analysis are summarized in Table 2. Pooling data from 9 studies, we found that MDA level was significantly higher in patients with OCD comparing to control groups $(\mathrm{SMD}=1.62 ; 95 \%$ CI $[0.53,2.72] ; \mathrm{I}^{2}=96.9 \%$; Pheterogeneity $\left.(\mathrm{Ph})<0.001\right)$. When we repeated our analysis among those studies that reported MDA levels in same unit, overall finding remained unchanged $(\mathrm{WMD}=1.93$; 95\% CI [0.27, 3.59]; $\mathrm{I}^{2}=99.2 \%$; Ph<0.001) (Fig. 2). Between-study heterogeneity was high among the included studies. We performed subgroup meta-analysis based on participants' country (Turkey and other countries) and study sample size (up to 60 and more than 60) to find possible sources of heterogeneity. Similar findings were also reached in all subgroups (Table 2).

\section{Discussion}

The current meta-analysis showed that MDA level was higher in OCD patients compared to control groups. This finding is in line with Maia et al. meta-analysis, where the same result was reached [24]. However, that study had numerous methodological limitations [25]. To solve those limitations, we added the missed studies. In addition, we have added more studies. Also, we have evaluated the MDA concentration alone. Jiménez-Fernández et al. (2015) and Liu et al. (2015) reported that the MDA level was higher in patients with depression disorder than controls [37, 38]. Moreover, Flatow et al. (2013) reported higher MDA levels in patients with schizophrenia than controls [39]. Other studies also showed significantly higher lipid peroxidation and nitric oxide in patients with psychological disorders than controls [40, 41]. In contrast with our study, Ranjekar et al. (2003) found no significant differences in serum levels of lipid peroxidation markers between patients with schizophrenic and healthy control [42]. Furthermore, Talarowska et al. (2011) did not find any significant association between plasma MDA 


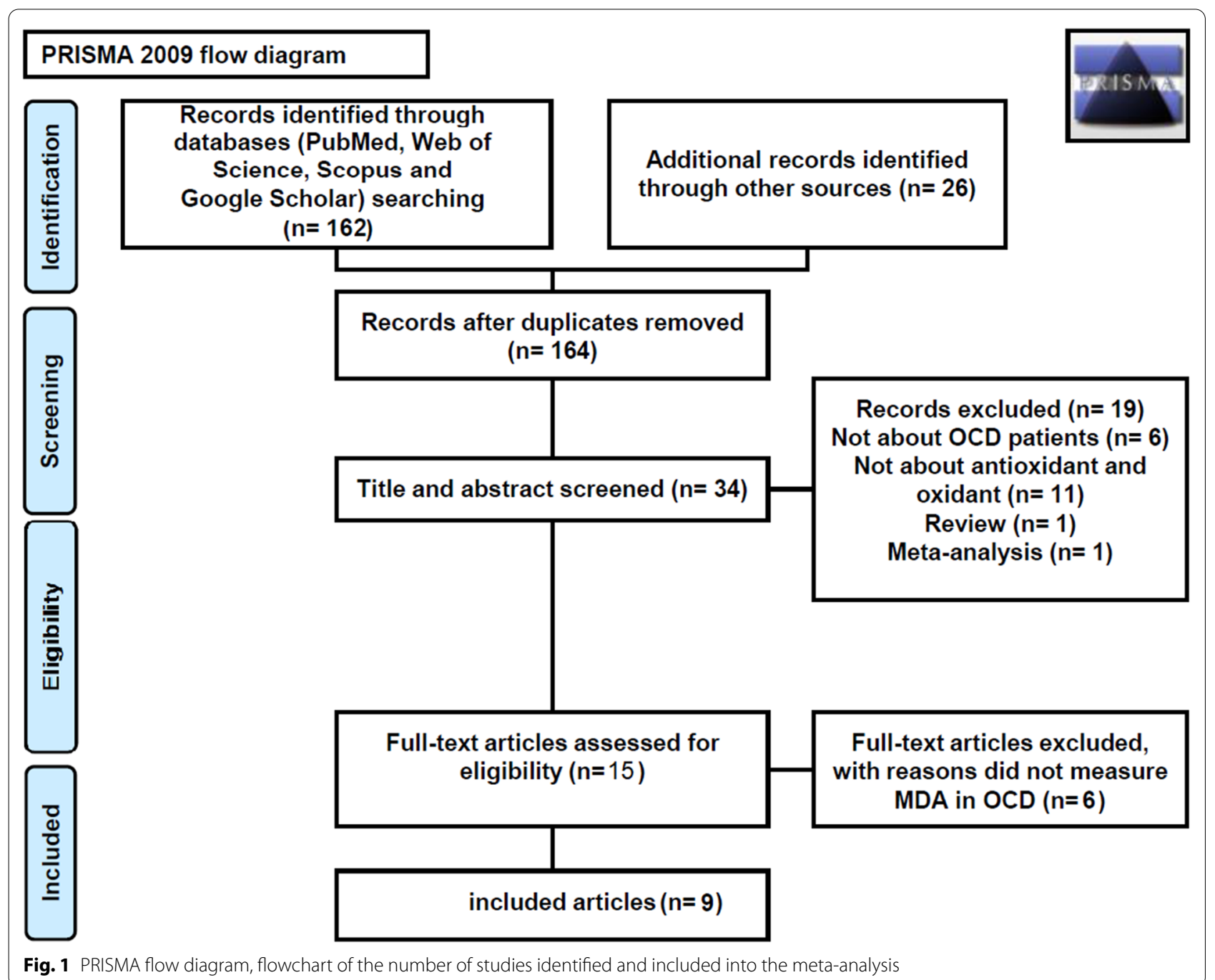

Table 2 Malondialdehyde concentration in relation to risk of obsessive-compulsive disorder by random effect model

\begin{tabular}{|c|c|c|c|c|c|c|c|c|}
\hline \multicolumn{3}{|c|}{ Malondialdehyde } & \multirow{2}{*}{$\begin{array}{l}\text { N studies } \\
9\end{array}$} & \multirow{2}{*}{$\begin{array}{l}\text { SMD } \\
1.62\end{array}$} & \multirow[t]{2}{*}{ WMD } & \multirow{2}{*}{$\begin{array}{l}\mathbf{9 5 \% ~ C l} \\
{[0.53,2.72]}\end{array}$} & \multirow{2}{*}{$\begin{array}{l}I^{2}(\%) \\
96.9\end{array}$} & \multirow{2}{*}{$\frac{P h}{<0.001}$} \\
\hline Different unit & Overall & & & & & & & \\
\hline & Country & Turkey & 4 & 2.46 & & {$[2.18,2.75]$} & 96.9 & $<0.001$ \\
\hline & & Other & 5 & 0.81 & & {$[0.55,21.06]$} & 95.6 & $<0.001$ \\
\hline & Sample size & $\leq 60$ & 5 & 1.24 & & {$[0.93,1.54]$} & 95.6 & $<0.001$ \\
\hline & & $>60$ & 4 & 1.73 & & {$[1.49,1.97]$} & 98.1 & $<0.001$ \\
\hline Same unit & & & 5 & & 1.93 & {$[0.27,3.59]$} & 99.2 & $<0.001$ \\
\hline
\end{tabular}

$\mathrm{Ph}(\mathrm{P}<0.1$ was considered as a significant difference), SMD Standardized Mean Difference, WMD weighted mean difference

levels and depressive disorder [43]. Oxidative markers are unspecific and can be influenced by numerous factors, such as body mass index, age, or smoking status [44-46]. Our subgroup analysis showed no overall change in our findings. However, due to the limited number of included studies in each subgroup, further studies are needed to reach a firm conclusion.
Although the exact mechanism of the association between OXS and OCD has not been clearly understood, some suggestions are made. ATP production in mitochondria by electron transport chain or through the respiratory burst of macronutrients in macrophages and neutrophils produce OXS [47]. Increased production of reactive oxygen species (ROS) overcomes 
A

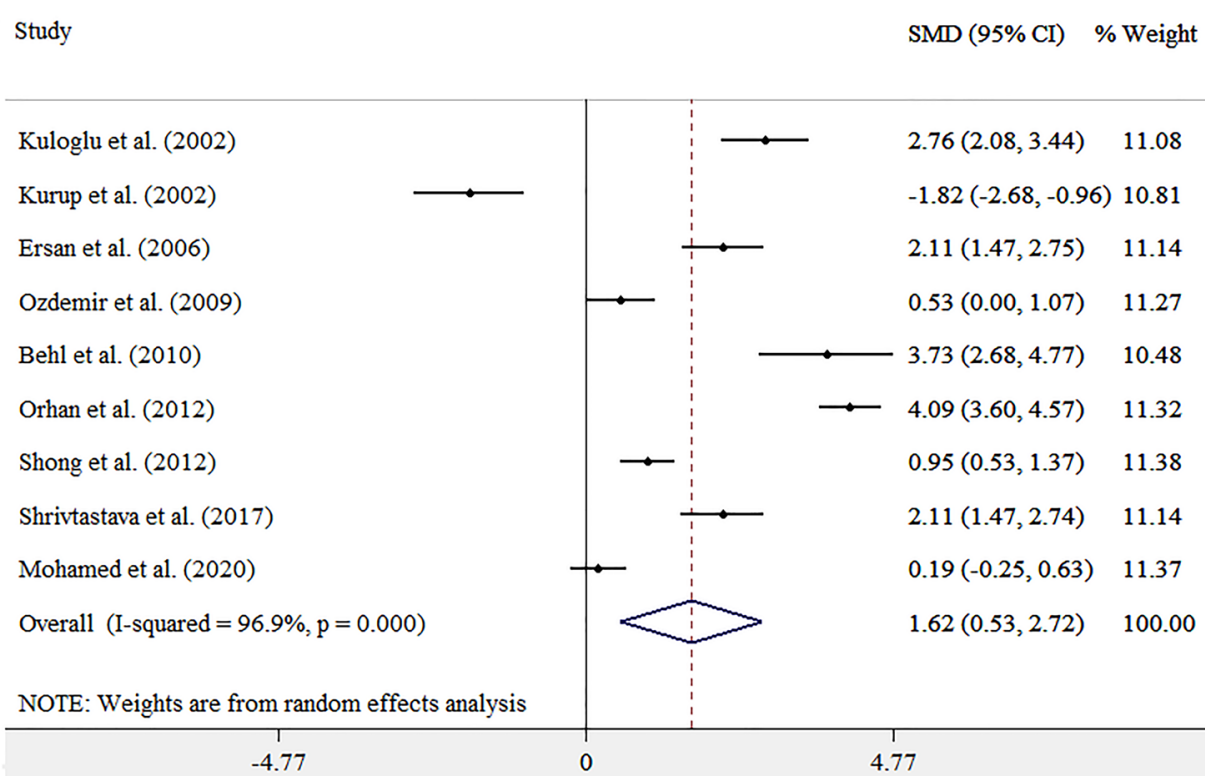

B

Study

$\operatorname{SMD}(95 \% \mathrm{CI}) \quad \%$ Weight

\begin{tabular}{|c|c|c|c|}
\hline Kuloglu et al. (2002) & 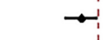 & $1.65(1.37,1.93)$ & 20.28 \\
\hline Behl et al. $(20: 0)$ & + & $0.82(0.68,0.96)$ & 20.37 \\
\hline Orhan et al. (2012) & & $\rightarrow 5.19(4.34 .5 .54)$ & 20.22 \\
\hline Shorg et al. (2012) & - & $1.40(0.31,1.99)$ & 19.89 \\
\hline Mnhamed et al (2020) & & $052 .(-038,143)$ & 192.4 \\
\hline Overall (I-squared $=99.2 \%, p=0.000)$ & & $1.93(0.27,3.59)$ & $100.0 \mathrm{C}$ \\
\hline NOTE: Weights are from random effects analysis & & & \\
\hline-5.54 & & 5.54 & \\
\hline
\end{tabular}

Fig. 2 Forest plot displaying mean difference and 95\% confidence intervals (Cl) for the MDA concentration $\mathbf{A}$ different unit, and $\mathbf{B}$ same unit, horizontal lines represent $95 \% \mathrm{Cl}$. Diamonds represent pooled estimates from random-effects analysis

antioxidant systems and causes injuries to the lipids, proteins, including some neurotransmitters (NT), and DNA [41]. Several NT containing dopamine, serotonin, gamma-aminobutyric acid, and glutamate have been shown to have regulatory roles in OCD [34]. Changes in these NT pathways may then increase oxidative reactions in the central nervous system [48]. Previous studies have shown that MDA reduces levels of serotonin in the brain [49]. OCD symptoms also result from some damages in the dopamine receptor-rich basal ganglia [50]. Also, OXS could at first be adaptive through enhancement of NT. However, that prolonged ROS generation could lead to exaggerated neurophysiological responses, with disruption of physiological NT [17] and increase of blood-brain barrier permeability, ultimately promoting neuroinflammation and neuronal death [51]. Furthermore, genetic factors might contribute to pathogenesis and symptoms of OCD [52, 53]. OCD is prevalent among those with mitochondrial dysfunctions induced by genetic disorders [34]. OXS is shown to be high among these subjects. 
This meta-analysis had several limitations. Firstly, the number of the included studies was insufficient to do subgroup analyses. Secondly, in the studies that MDA concentrations were reported as $\mu \mathrm{m}$ per $\mathrm{mg}$ of protein or hemoglobin, we needed mean protein or hemoglobin concentrations to convert these values to $\mu \mathrm{m}$. We asked the first authors or study corresponding authors to send us the necessary data, but no response was received. Thirdly, differences in study location and limited number of participants were other limitations. Fourthly, findings were not adjusted for several important confounding factors, such as dietary intakes, body mass index, and smoking status. Fifthly, studies used different laboratory methods to measure MDA serum levels and diagnose OCD, so this should be concerned as a source of bias. Finally, most included studies were done among a certain population (Turkish).

In conclusion, our study showed that MDA levels in patients with OCD were higher than in healthy controls. Studies have shown that antidepressant agents, which are commonly used in OCD patients, reduce oxidative stress markers in the body [54, 55]. The current study showed that oxidative stress was high in these patients. Therefore, it might be suggested that measurement of oxidative stress markers in these patients will be a treatment biomarker for the future. Further investigations (among different nations) are required to shed light on the role of OXS in OCD initiation and pathogenesis.

\section{Acknowledgements}

We thank all advisers. This work was supported by the Vice-Chancellor for Research, Kashan University of Medical science, Kashan, Iran.

\section{Authors' contributions}

AHM and EB designed the study. AHM and EB collected data. AHM and AM analyzed data and wrote the manuscript. All authors read and approved the final manuscript.

\section{Funding}

None.

\section{Availability of data and materials}

Data and material will be provided upon request.

\section{Declarations}

Ethics approval and consent to participate

Not applicable.

\section{Consent for publication \\ Not applicable.}

\section{Competing interests}

The authors had no competing interests.

\section{Author details}

${ }^{1}$ Student Research Committee, Kashan University of Medical Sciences, Kashan, Iran. ${ }^{2}$ Research Center for Biochemistry and Nutrition in Metabolic Diseases, Institute for Basic Sciences, Kashan University of Medical Sciences (KAUMS),
Kashan, Iran. ${ }^{3}$ Department of Clinical Psychology, School of Medicine, Kashan University of Medical Sciences, Kashan, Iran.

Received: 6 February 2021 Accepted: 2 June 2021

Published online: 16 June 2021

\section{References}

1. Association AP: Diagnostic and statistical manual of mental disorders (DSM- $5^{\circledR}$ ): American Psychiatric Pub; 2013.

2. Abramovitch A, McCormack B, Brunner D, Johnson M, Wofford N. The impact of symptom severity on cognitive function in obsessive-compulsive disorder: A meta-analysis. Clin Psychol Rev. 2019;67:36-44.

3. Ruscio AM, Stein DJ, Chiu WT, Kessler RC. The epidemiology of obsessivecompulsive disorder in the National Comorbidity Survey Replication. Mol Psychiatry. 2010;15(1):53.

4. Balandeh E, Karimian M, Behjati M, Mohammadi AH: Serum Vitamins and Homocysteine Levels in Obsessive-Compulsive Disorder: A Systematic Review and Meta-Analysis. Neuropsychobiology 2021:1-14.

5. Hollander E, Stein DJ, Broatch J, Rowland CT, Himelein CA. Obsessivecompulsive and spectrum disorders: overview and quality of life issues. J Clin Psychiatry. 1996;57((Suppl 8)):3-6.

6. Hollander E. Treatment of obsessive-compulsive spectrum disorders with SSRIs. Br J Psychiatry. 1998;173(S35):7-12.

7. Stein DJ, Roberts M, Hollander E, Rowland C, Serebro P. Quality of life and pharmaco-economic aspects of obsessive-compulsive disorder A South African survey. South Afr Med J. 1996;86(12 Suppl):1582-1575.

8. Cicek E, Cicek IE, Kayhan F, Uguz F, Kaya N. Quality of life, family burden and associated factors in relatives with obsessive-compulsive disorder. Gen Hosp Psychiatry. 2013:35(3):253-8.

9. Kar SK, Choudhury I. An empirical review on oxidative stress markers and their relevance in obsessive-compulsive disorder. Int J Nutri Pharmacol Neurol Dis. 2016;6(4):139.

10. Hassan W. Eduardo Barroso Silva C, Mohammadzai IU, Batista Teixeira da Rocha J, Landeira-Fernandez J. Association of oxidative stress to the genesis of anxiety: implications for possible therapeutic interventions. Curr Neuropharmacol. 2014. 12(2):120-39.

11. Yllmaz ED. Üstündağ MF, Gençer AG, Kivrak Y, Ünal Ö, Bilici M. Levels of nitric oxide, asymmetric dimethyl arginine, symmetric dimethyl arginine, and $\mathrm{L}$-arginine in patients with obsessive-compulsive disorder. Turkish J Med Sci. 2016.46(3):775-82.

12. Milajerdi A, Shakeri F, Keshteli AH, Mousavi SM, Benisi-Kohansal S, Saadatnia M, Esmaillzadeh A. Dietary total antioxidant capacity in relation to stroke among Iranian adults. Nutr Neurosci. 2020;23(6):465-70.

13. Milajerdi A, Keshteli AH, Afshar H, Esmaillzadeh A, Adibi P. Dietary total antioxidant capacity in relation to depression and anxiety in Iranian adults. Nutrition. 2019;65:85-90.

14. Bouayed J, Rammal H, Soulimani R. Oxidative stress and anxiety: relationship and cellular pathways. Oxid Med Cell Longev. 2009;2(2):63-7.

15. Maes M, Kubera M, Leunis JC, Berk M, Geffard M, Bosmans E. In depression, bacterial translocation may drive inflammatory responses, oxidative and nitrosative stress (O\&NS), and autoimmune responses directed against O\&NS-damaged neoepitopes. Acta Psychiatr Scand. 2013;127(5):344-54

16. Miller MW, Lin AP, Wolf EJ, Miller DR. Oxidative stress, inflammation, and neuroprogression in chronic PTSD. Harv Rev Psychiatry. 2018;26(2):57.

17. Schiavone S, Jaquet V, Trabace L, Krause K-H. Severe life stress and oxidative stress in the brain: from animal models to human pathology. Antioxid Redox Signal. 2013;18(12):1475-90.

18. Uttara B, Singh AV, Zamboni P, Mahajan R. Oxidative stress and neurodegenerative diseases: a review of upstream and downstream antioxidant therapeutic options. Curr Neuropharmacol. 2009;7(1):65-74.

19. Alvarez-Arellano L, González-García N, Salazar-García M, Corona JC. Antioxidants as a potential target against inflammation and oxidative stress in attention-deficit/hyperactivity disorder. Antioxidants. 2020;9(2):176.

20. Ayala A, Muñoz MF, Argüelles S. Lipid peroxidation: production, metabolism, and signaling mechanisms of malondialdehyde and 4-hydroxy2-nonenal. Oxidative Med Cell Longevity. 2014. https://doi.org/10.1155/ $2014 / 360438$ 
21. Islam MT. Oxidative stress and mitochondrial dysfunction-linked neurodegenerative disorders. Neurol Res. 2017;39(1):73-82.

22. Shohag MH, Ullah MA, Azad MA, Islam MS, Qusar S, Shahid SF, Hasnat A. Serum antioxidant vitamins and malondialdehyde levels in patients with obsessive-compulsive disorder. German J Psychiatr. 2012. 15(1).

23. Ersan S, Bakir S, Ersan EE, Dogan O. Examination of free radical metabolism and antioxidant defence system elements in patients with obsessive-compulsive disorder. Prog Neuropsychopharmacol Biol Psychiatry. 2006:30(6):1039-42.

24. Maia A, Oliveira J, Lajnef M, Mallet L, Tamouza R, Leboyer M, Oliveira-Maia AJ. Oxidative and nitrosative stress markers in obsessive-compulsive disorder: a systematic review and meta-analysis. Acta Psychiatr Scand. 2019;139(5):420-33.

25. Mohammadi AH, Balandeh E, Milajerdi A: Letter to the Editor: Reanalysis is needed for the "Oxidative and Nitrosative Stress Markers in ObsessiveCompulsive Disorder: A Systematic Review and Meta-Analysis". Acta Psychiatr Scand 2019.

26. Ozdemir E, Cetinkaya S, Ersan S, Kucukosman S, Ersan EE. Serum selenium and plasma malondialdehyde levels and antioxidant enzyme activities in patients with obsessive-compulsive disorder. Prog Neuropsychopharmacol Biol Psychiatry. 2009;33(1):62-5.

27. Kurup RK, Kurup PA. Hypothalamic digoxin deficiency In obsessive compulsive disorder and La Tourette S syndrome. Int J Neurosci. 2002;112(7):797-816.

28. Oliveira J, Maia A, Lajnef M, Mallet L, Tamouza R, Leboyer M, Oliveira-Maia AJ. Opportunities and challenges in meta-analyses of oxidative and nitrosative stress markers in neuropsychiatric disorders. Acta Psychiatr Scand. 2020;141(1):89-90.

29. Moher D, Liberati A, Tetzlaff J, Altman DG. Preferred reporting items for systematic reviews and meta-analyses: the PRISMA statement. J Clin Epidemiol. 2009;62(10):1006-12.

30. Shrivastava A, Tripathy AK, Dalal PK. A SVM-based classification approach for obsessive compulsive disorder by oxidative stress biomarkers. J Comput Sci. 2019;36:101023

31. Peterson J, Welch V, Losos M, Tugwell P. The Newcastle-Ottawa scale (NOS) for assessing the quality of nonrandomised studies in meta-analyses. Ottawa: Ottawa Hospital Research Institute; 2011.

32. Behl A, Swami G, Sircar S, Bhatia M, Banerjee B. Relationship of possible stress-related biochemical markers to oxidative/antioxidative status in obsessive-compulsive disorder. Neuropsychobiology. 2010;61(4):210-4.

33. Kuloglu M, Atmaca M, Tezcan E, Gecici Ö, Tunckol H, Ustundag B. Antioxidant enzyme activities and malondialdehyde levels in patients with obsessive-compulsive disorder. Neuropsychobiology. 2002;46(1):27-32.

34. Orhan N, Kucukali Cl, Cakir U, Seker N, Aydin M. Genetic variants in nuclear-encoded mitochondrial proteins are associated with oxidative stress in obsessive compulsive disorders. J Psychiatr Res. 2012:46(2):212-8.

35. Shrivastava A, Kar SK, Sharma E, Mahdi AA, Dalal PK. A study of oxidative stress biomarkers in obsessive compulsive disorder. J Obsessive-Compuls Relat Disord. 2017;15:52-6. https://doi.org/10.1016/j.jocrd.2017.09.004.

36. Mohammed MA, Hilal NN, Al Ani AH. Serum levels of oxidative stress biomarkers in patients obsessive compulsive disorder in Tikrit City, Iraq. Indian J Public Health Res Develop. 2019:10(10):1152-6.

37. Jimenez-Fernandez S, Gurpegui M, Diaz-Atienza F, Perez-Costillas L, Gerstenberg M, Correll CU. Oxidative stress and antioxidant parameters in patients with major depressive disorder compared to healthy controls before and after antidepressant treatment: results from a meta-analysis. J Clin Psychiatry. 2015;76(12):1658-67.

38. Liu T, Zhong S, Liao X, Chen J, He T, Lai S, Jia Y. A meta-analysis of oxidative stress markers in depression. PLoS ONE. 2015;10(10):0138904.

39. Flatow J, Buckley P, Miller BJ. Meta-analysis of oxidative stress in schizophrenia. Biol Psychiat. 2013;74(6):400-9.
40. Andreazza AC, Kauer-Sant'Anna M, Frey BN, Bond DJ, Kapczinski F, Young LT, Yatham LN. Oxidative stress markers in bipolar disorder: a meta-analysis. J Affect Disord. 2008;111(2-3):135-44.

41. Brown NC, Andreazza AC, Young LT. An updated meta-analysis of oxidative stress markers in bipolar disorder. Psychiatry Res. 2014;218(1-2):61-8.

42. Ranjekar PK, Hinge A, Hegde MV, Ghate M, Kale A, Sitasawad S, Wagh UV, Debsikdar VB, Mahadik SP. Decreased antioxidant enzymes and membrane essential polyunsaturated fatty acids in schizophrenic and bipolar mood disorder patients. Psychiatry Res. 2003;121(2):109-22.

43. Talarowska M, Gałecki P, Maes M, Gardner A, Chamielec M, Orzechowska A, Bobińska K, Kowalczyk E. Malondialdehyde plasma concentration correlates with declarative and working memory in patients with recurrent depressive disorder. Mol Biol Rep. 2012;39(5):5359-66.

44. Isik B, Ceylan A, Isik R. Oxidative stress in smokers and non-smokers. Inhalation Toxicol. 2007;19(9):767-9.

45. Wonisch W, Falk A, Sundl I, Winklhofer-Roob BM, Lindschinger M. Oxidative stress increases continuously with $\mathrm{BMI}$ and age with unfavourable profiles in males. Aging Male. 2012;15(3):159-65.

46. Milajerdi A, Larijani B, Esmaillzadeh A. Statins influence biomarkers of low grade inflammation in apparently healthy people or patients with chronic diseases: a systematic review and meta-analysis of randomized clinical trials. Cytokine. 2019;123:154752.

47. Inoguchi T, Sonta T, Tsubouchi H, Etoh T, Kakimoto M, Sonoda N, Sato N, Sekiguchi N, Kobayashi K, Sumimoto H. Protein kinase C-dependent increase in reactive oxygen species (ROS) production in vascular tissues of diabetes: role of vascular NAD (P) H oxidase. J Am Soc Nephrol. 2003:14(suppl 3):S227-32.

48. Dean OM. den Buuse Mv, Bush A, Copolov D, Ng F, Dodd S, Berk M: A role for glutathione in the pathophysiology of bipolar disorder and schizophrenia? Animal models and relevance to clinical practice. Curr Med Chem. 2009:16(23):2965-76.

49. Brambilla F, Bellodi L, Perna G, Arancio C, Bertani A. Dopamine function in obsessive-compulsive disorder: Growth hormone response to apomorphine stimulation. Biol Psychiat. 1997;42(10):889-97.

50. Carmin CN, Wiegartz PS, Yunus U, Gillock KL. Treatment of late-onset OCD following basal ganglia infarct. Depress Anxiety. 2002;15(2):87-90.

51. Gu Y, Dee CM, Shen J. Interaction of free radicals, matrix metalloproteinases and caveolin-1 impacts blood-brain barrier permeability. Front Biosci (Schol Ed). 2011;3(3):1216-31.

52. Taylor S. Disorder-specific genetic factors in obsessive-compulsive disorder: A comprehensive meta-analysis. Am J Med Genet B Neuropsychiatr Genet. 2016:171(3):325-32.

53. Walitza S, Bové DS, Romanos M, Renner T, Held L, Simons M, Wewetzer C, Fleischhaker C, Remschmidt H, Warnke A. Pilot study on HTR2A promoter polymorphism,- 1438G/A (rs6311) and a nearby copy number variation showed association with onset and severity in early onset obsessivecompulsive disorder. J Neural Transm. 2012;119(4):507-15.

54. Jiménez-Fernández S, Gurpegui M, Diaz-Atienza F, Pérez-Costillas L, Gerstenberg M, Correll CU. Oxidative stress and antioxidant parameters in patients with major depressive disorder compared to healthy controls before and after antidepressant treatment: results from a meta-analysis. J Clin Psychiatry. 2015;76(12):1658-67.

55. Chakraborty S, Dasgupta A, Das HN, Singh OP, Mandal AK, Mandal N. Study of oxidative stress in obsessive compulsive disorder in response to treatment with Fluoxetine. Indian J Clin Biochem. 2009;24(2):194-7.

\section{Publisher's Note}

Springer Nature remains neutral with regard to jurisdictional claims in published maps and institutional affiliations. 